С.С. Рязанцев, Д.М. Литовченко, О.М. Мішуков

Харківський національний університет Повітряних Сил ім. І. Кожедуба, Харків

\title{
ОЦІНЮВАННЯ ЕФЕКТИВНОСТІ БОЙОВОГО ЗАСТОСУВАННЯ РОЗВІДУВАЛЬНО-УДАРНОЇ СИСТЕМИ З ВРАХУВАННЯМ ТЕХНІЧНИХ ХАРАКТЕРИСТИК СИСТЕМ РОЗВІДКИ ТА УПРАВЛІННЯ
}

У сьогоденні в час швидкого розвитку озброєння і військової техніки, підвищення інтенсивності процесу ведення бойових дій (операцій) багато уваги приділяється питанням оцінювання ефективності розвідувально-ударних систем, які складаються з систем розвідки, управління та засобів вогневого ураження. В статті розглянуто прочес функиіонування розвідувально-ударної системи, з врахуванням впливу технічних характеристик системи розвідки та системи управління з метою розробки методики оцінювання ефективності ї̈ бойового застосування.

Ключові слова: розвідувально-ударна система, система розвідки, системи управління, вогневі засоби, ефективність.

\section{Вступ}

Постановка проблеми. Сучасні тенденції ведення збройної боротьби свідчать про пріоритетність розвідувально-ударних операцій, підвищення ролі саме мобільних комплексів озброєння у здійсненні вогневого ураження противника. Наявність відповідної зброї у збройних силах держав з оборонною воєнною доктриною є надійним фактором стримування можливої агресії та запобігання посиленню загрози національній безпеці. Одним з основних напрямів їх розвитку $\epsilon$ інтеграція технічних засобів розвідки, засобів автоматизованого управління та засобів ураження в єдину функціональну систему, здатну виявляти та уражати об'єкти противника в реальному масштабі часу бою. При створенні подібних систем озброєння виникає проблема кількісного оцінювання ефективності бойового застосування засобів вогневого ураження (вогневих засобів) з врахуванням впливу технічних характеристик системи розвідки та системи управління.

Аналіз останніх досліджень і публікацій. В багатьох роботах [1-9] ефективність бойового застосування засобів вогневого ураження, ефективність системи розвідки та системи управління досліджуються відокремлено. В тих роботах, де ефективність бойового застосування засобів вогневого ураження розвідувально-ударної системи (РУС) оцінюється 3 врахуванням впливу функціонування систем розвідки та управління, цей вплив, як правило, враховується опосередковано.

Метою статті $\epsilon$ розробка методики оцінювання ефективності бойового застосування засобів вогневого ураження РУС з врахуванням впливу технічних характеристик системи розвідки та системи управління.

\section{Виклад основного матеріалу}

Розглянемо автономне функціонування РУС, яка складається з системи розвідки, системи управління та засобів вогневого ураження. Під автономним функціонуванням будемо розуміти функціонування системи при відсутності сторонніх керуючих впливів. Метою функціонування РУС є ураження максимальної кількості цілей певного типу в призначеній їй зоні відповідальності. В якості показника ефективності системи оберемо ймовірність обстрілу цілі. Інтенсивність появи нових цілей у зоні дії РУС позначимо як $\lambda$. Характеристикою системи розвідки $є$ можливість виявлення в розташуванні противника $\mu_{1}$ цілей за одиницю часу. Проміжки часу між моментами виявлення цілей та час обробки інформації по кожній цілі величина випадкова $\Delta t$. Виявлення цілей за одиницю часу складають простіший потік. Дані розвідки надходять до системи управління (СУ), яка має обмежену пропускну здатність $\mu_{2}$ за одиницю часу. Отримані дані розподіляються між вогневими засобами (В3) для знищення наземних (повітряних) цілей противника. Значення показників $\mu_{1}$ i $\mu_{2}$ залежить від характеристик технічних засобів, що входять до складу системи. Нехай час перебування цілей в зоні дії В3 приблизно дорівнює часу необхідного виявлення, обробки інформації та ураження цих цілей. У першому наближенні систему можна вважати системою з відмовами [4; 6].

Система управління може перебувати в таких можливих станах ймовірності $P_{i j}$ :

$P_{00}$ - імовірність того, що системи розвідки і управління вільні;

$P_{10}$ - імовірність того, що система розвідки за- 
йнята, бо отримує інформацію про одну з виявлених цілей, система управління вільна;

$P_{01}$ - імовірність того, що система розвідки вільна, система управління зайнята обробкою інформації про ціль;

$P_{11}$ - імовірність того, що обидві системи зайняті. Диференційні рівняння станів системи $S_{i j}$ в залежності від імовірних випадків функціонування має вигляд:

$S_{00}$ - стан системи, за якого системи розвідки і управління вільні;

$S_{10}$ - стан системи, за якого система розвідки зайнята бо отримує інформацію про одну з виявлених цілей, система управління вільна;

$S_{01}$ - стан системи, за якого система розвідки вільна, система управління зайнята обробкою інформації про ціль;

$S_{11}$ - стан системи, за якого обидві системи зайняті.

Опишемо стан системи $S_{00}$, який можливий у таких випадках:

- система розвідки і управління вільні під час $t$. На протязі $\Delta t$ не виявлено жодної цілі. Імовірність переходу до стану $S_{00}-P_{00}(t)(1-\lambda \Delta t)$;

- загальна система за годину $t$ знаходилась у стані $S_{01}$.

За час $\Delta t$ інформація про ціль передана В3 для ii знищення. Імовірність переходу до стану $S_{00}-$ $P_{01}(t) \mu_{2} \Delta t$.

Рівняння імовірності стану $S_{00}$ можливо записати як $P_{00}(t+\Delta t)=P_{00}(t)(1-\lambda \Delta t)+P_{01}(t) \mu_{2} \Delta t$, тоді маємо диференційне рівняння для розрахунків імовірності знаходження системи в стані $S_{00}$ :

$$
\frac{d P_{00}(t)}{d t}=-P_{00}(t) \lambda+P_{01}(t) \mu_{2}
$$

Опишемо стан системи $S_{01}$, який можливий у таких випадках:

- система була в стані $S_{01}$.

За час $\Delta t$ не виявлено нових цілей і система управління не обробила дані ні по одній цілі. Імовірність переходу до стану $S_{01}$ $P_{01}(t)(1-\lambda \Delta t)\left(1-\mu_{2} \Delta t\right) ;$

- система знаходилася в стані $S_{10}$. За час $\Delta t$ система розвідки виявила і видала дані по цілі системі управління. Імовірність переходу до стану $S_{01}$ $-P_{10}(t) \mu_{1} \Delta t$;

- під час $t$ система знаходилася в стані $S_{11}$. За час $\Delta t$ система розвідки виявила і видала дані по цілі до СУ. СУ не використала їх тому що була за- йнята обробкою даних про попередню ціль. Отримані дані втрачені внаслідок короткочасного перебування цілі в зоні дії В3. Імовірність переходу до стану $S_{01}-P_{11}(t) \mu_{1} \Delta t$.

Диференційне рівняння імовірності знаходження системи в стані $S_{01}$ запишемо як:

$$
\frac{d P_{01}(t)}{d t}=-\left(\lambda+\mu_{2}\right) P_{01}(t)+\mu_{1} P_{11}(t)+\mu_{1} P_{10}(t) .
$$

Опишемо стан системи $S_{10}$, який можливий у таких випадках:

- під час $t$ система знаходилася в стані $S_{00}$. За час $\Delta t$ система розвідки виявила ціль. Імовірність переходу до стану $S_{10}-P_{00}(t) \lambda \Delta t$;

- під час $t$ система знаходилася в стані $S_{10}$. За час $\Delta t$ система розвідки не обробила інформацію по цілі і не передала дані в СУ. Імовірність переходу до стану $S_{10}-P_{10}(t)\left(1-\mu_{1} \Delta t\right)$;

- під час $t$ система знаходилася в стані $S_{11}$. За час $\Delta t$ СУ видала дані для обстрілу цілі. Імовірність переходу до стану $S_{10}-P_{11}(t) \mu_{2} \Delta t$.

Після перетворень диференційне рівняння імовірності знаходження системи в стані $S_{10}$ запишемо як:

$$
\frac{d P_{10}(t)}{d t}=\lambda P_{00}(t)-\mu_{1} P_{10}(t)+\mu_{2} P_{11}(t) \text {. }
$$

Опишемо стан системи $S_{11}$, який можливий у таких випадках:

- система знаходиться в стані $S_{01}$. За час $\Delta t$ отримані нові дані щодо цілі. Імовірність переходу до стану $S_{11}-P_{01}(t) \lambda \Delta t$;

- система знаходиться в стані $S_{11}$. За час $\Delta t$ не були оброблені дані по цілі системами розвідки і управління. Імовірність переходу до стану $S_{11}$

$$
P_{11}(t)\left[1-\left(\mu_{1}+\mu_{2}\right) \cdot \Delta t\right] .
$$

Після перетворень диференційне рівняння імовірності знаходження системи в стані $S_{11}$ запишемо як

$$
\frac{d P_{11}(t)}{d t}=\lambda P_{01}(t)-\left(\mu_{1}+\mu_{2}\right) P_{11}(t) .
$$

Перераховані стани системи описуються сукупністю диференційних рівнянь (1-4):

$$
\begin{gathered}
\frac{d P_{00}(t)}{d t}=-P_{00}(t) \lambda+P_{01}(t) \mu_{2} ; \\
\frac{d P_{01}(t)}{d t}=-\left(\lambda+\mu_{2}\right) P_{01}(t)+\mu_{1} P_{11}(t)+\mu_{1} P_{10}(t) ; \\
\frac{d P_{10}(t)}{d t}=\lambda P_{00}(t)-\mu_{1} P_{10}(t)+\mu_{2} P_{11}(t) ; \\
\frac{d P_{11}(t)}{d t}=\lambda P_{01}(t)-\left(\mu_{1}+\mu_{2}\right) P_{11}(t) .
\end{gathered}
$$




$$
\text { При } t \rightarrow \infty, \quad \frac{d P_{i j}(t)}{d t} \rightarrow 0, \quad P_{i j}(t) \rightarrow P_{i j}=\text { const }
$$

диференційні рівняння (5) перетворюються в алгебраїчні:

$$
\begin{aligned}
& P_{00} \lambda=\mu_{2} P_{01}, \quad P_{01}\left(\lambda+\mu_{2}\right)=\mu_{1} P_{11}+\mu_{1} P_{10}, \\
& P_{10} \mu=\lambda P_{00}+P_{11} \mu_{2}, \quad\left(\mu_{1}+\mu_{2}\right) P_{11}=\lambda P_{01} .
\end{aligned}
$$

Рішення (6) відносно $P_{i j}$, дає імовірність різних станів складної системи:

$$
\begin{aligned}
& P_{00}=\frac{\mu_{1} \mu_{2}}{\left(\mu_{2}+\lambda\right)\left(\mu_{1}+\lambda\right)} ; \\
& P_{10}=\frac{\lambda \mu_{2}\left(\mu_{1}+\mu_{2}+\lambda\right)}{\left(\mu_{1}+\mu_{2}\right)\left(\mu_{1}+\lambda\right)\left(\mu_{2}+\lambda\right)} ; \\
& P_{01}=\frac{\lambda \mu_{1}}{\left(\mu_{2}+\lambda\right)\left(\mu_{1}+\lambda\right)} ; \\
& P_{11}=\frac{\mu_{1} \lambda^{2}}{\left(\mu_{1}+\lambda\right)\left(\mu_{2}+\lambda\right)\left(\mu_{1}+\mu_{2}\right)} .
\end{aligned}
$$

Імовірність пропуску (відмови) цілі, тобто того, що ціль не буде виявлена, не буде обстріляна й виконає бойову задачу, дорівнює

$$
P_{\text {npon }}=1-\frac{\mu_{2}\left(P_{01}+P_{11}\right)}{\lambda} .
$$

Визначимо ефективність РУС, як імовірність $P$ обстрілу кожної цілі, що з'являється.

$$
P=1-P_{\text {npon }} \text {. }
$$

Оцінка ефективності $P$ розвідувально-ударної системи в залежності від кількості $\lambda \frac{\text { цілей }}{\text { oд.часу }}$, що з'являються в смузі дії системи розвідки і управлін-

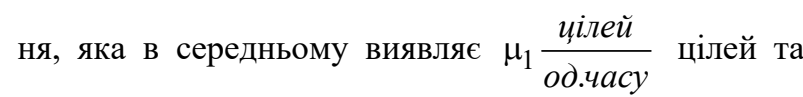
обробляє і планує стрільбу В3 у середньому по $\mu_{2} \frac{\text { цุiлям }}{\text { од.часу }}$, надана в табл. 1.
Таблиця 1

Ефективність ( $P$ ) розвідувально-ударної системи з врахуванням технічних характеристик систем розвідки та управління

\begin{tabular}{|c|c|c|c|c|c|c|}
\hline \multirow{2}{*}{$\lambda$} & \multirow{2}{*}{$\mu_{1}$} & \multicolumn{5}{|c|}{$\mu_{2}$} \\
\cline { 3 - 7 } & & 2 & 4 & 6 & 8 & 10 \\
\hline \multirow{4}{*}{2} & 2 & 0.375 & 0.444 & 0.469 & 0.480 & 0.486 \\
\cline { 2 - 7 } & 4 & 0.444 & 0.556 & 0.600 & 0.622 & 0.635 \\
\cline { 2 - 7 } & 6 & 0.469 & 0.600 & 0.656 & 0.686 & 0.703 \\
\cline { 2 - 7 } & 8 & 0.480 & 0.622 & 0.686 & 0.720 & 0.741 \\
\hline \multirow{4}{*}{4} & 2 & 0.222 & 0.278 & 0.0300 & 0.311 & 0.317 \\
\cline { 2 - 7 } & 4 & 0.278 & 0.375 & 0.420 & 0.444 & 0.456 \\
\cline { 2 - 7 } & 6 & 0.300 & 0.420 & 0.480 & 0.514 & 0.536 \\
\hline \multirow{4}{*}{8} & 8 & 0.311 & 0.444 & 0.514 & 0.556 & 0.582 \\
\hline & 2 & 0.156 & 0.200 & 0.219 & 0.229 & 0.234 \\
\cline { 2 - 7 } & 4 & 0.200 & 0.280 & 0.320 & 0.343 & 0.357 \\
\cline { 2 - 7 } & 6 & 0.219 & 0.320 & 0.375 & 0.408 & 0.430 \\
\hline & 8 & 0.229 & 0.343 & 0.408 & 0.449 & 0.476 \\
\hline \multirow{4}{*}{8} & 2 & 0.120 & 0.156 & 0.171 & 0.180 & 0.185 \\
\cline { 2 - 7 } & 4 & 0.156 & 0.222 & 0.257 & 0.278 & 0.291 \\
\cline { 2 - 7 } & 6 & 0.171 & 0.257 & 0.306 & 0.337 & 0.357 \\
\cline { 2 - 7 } & 8 & 0.180 & 0.278 & 0.337 & 0.375 & 0.401 \\
\hline
\end{tabular}

Джерело: розроблено авторами.

\section{Висновки}

Таким чином, завдання оцінювання ефективності бойового застосування РУС, яка складається 3 систем розвідки, управління та засобів вогневого ураження розв'язане із застосуванням відомого апробованого математичного апарату. Задіяні в розрахунках величини мають ясний фізичний смисл. Розроблена методика дозволяє виявляти вплив технічних характеристик системи розвідки та системи управління вогневими засобами на ефективність РУС в цілому та обгрунтовувати вимоги до тактикотехнічних характеристик перспективних систем озброєння їх систем розвідки, управління та вогневого ураження.

\section{Список літератури}

1. Матвеев С. И. Высокоточные системы РВ и А: перспективы и основные направления работ по созданию разведывательно-ударных и разведывательно-огневых комплексов. Военная мыслль. 2005. № 2. С. 2-27.

2. Байбаков А. И., Зебзеев А. А. Состояние и перспективы развития воздушной разведки иностранных государств. Военная мысль. 2021. №. 2. С. 120-140.

3. Волков Е. Б., Дворкин В. З., Прокудин А. И., Шишкин Ю. Н. Технические основы эффективности ракетных систем. Москва : Машиностроение, 1989. 256 с.

4. Клейнрок Л. Теория массового обслуживания. Москва : Машиностроение, 1979. 432 с.

5. Сурмин Ю. П. Теория систем и системный анализ : учеб. пособие. Киев : МАУП, 2003. 213 с.

6. Греков В. П. Оцінювання ефективності бойового застосування засобів ураження з врахуванням впливу технічних характеристик систем розвідки та управління. Збірник наукових праць Об'єднаного науково-дослідного інституту. 2005. № 2(2). С. 79-84.

7. Бархударян М. В. Визначення основних тактико-технічних характеристик вимірювальних засобів полігонного вимірювально-обчислювального комплексу, які впливають на рівень безпеки при проведенні бойових стрільб, пусків ракет, бомбометання та полігонних випробувань. Системи озброєння і військова техніка. 2010. № 3(23). С. $19-21$.

8. Бархударян М. В., Чумак Б. О., Мішуков О. М. Математична модель побудови перспективного полігонного вимірювально-обчислювального комплексу. Наука і техніка Повітряних Сил Збройних Сил Украӥни. 2012. № 2(8). С. 57-59.

9. Чумак Б. О., Нос О. М., Мішуков О. М. Аналіз похибок трьохпараметричних вимірювальних систем. Наука $i$ техніка Повітряних Сил Збройних Сил Украӥни. 2014. № 3(16). С. 125-128.

10. Lukianchuk V., Lanetskii B., Khudov H., Zvieriev O., Terebuha I., Kuprii V., Artemenko A., Aristarkhov O., Kondratenko Y. Development of the combined method for evaluating and controlling the reliability indicator "probability of 
failure-free switching" of a radio technical complex. Eastern-European Journal of Enterprise Technologies. 2021. No. 1/9(109). P. 6-17. https://doi.org/10.15587/1729-4061.2021.225484.

11. Загорка О. М., Колесников В. В., Коваль І. О. До питання застосування розвідувально-ударних і розвідувально вогневих комплексів у мережецентричній війні. Наука і техніка Повітряних Сил Збройних Сил України. 2012. № 3. С. 8-13.

12. Семененко О. М., Ремез А. В., Романченко О. А., Бондаренко О. С. Загальна структурно-логічна схема та зміст методики воєнно-економічного обгрунтування вибору раціонального варіанту розвідувально-ударної системи для Збройних Сил України. Збірник наукових праць Центрального науково-дослідного інституту Збройних Сил України. 2021. № 4(95). C. 36-45.

\section{Відомості про авторів:}

Рязанцев Сергій Сергійович викладач

Харківського національного університету

Повітряних Сил ім. І. Кожедуба,

Харків, Україна

https://orcid.org/0000-0003-3049-2547

Литовченко Дмитро Михайлович кандидат технічних наук старший викладач кафедри

Харківського національного університету

Повітряних Сил ім. І. Кожедуба,

Харків, Україна

https://orcid.org/0000-0001-5154-6060

Мішуков Олександр Михайлович доцент кафедри

Харківського національного університету

Повітряних Сил ім. І. Кожедуба,

Харків, Україна

https://orcid.org/0000-0001-6101-122X
Information about the authors:

\author{
Serhii Riazantsev \\ Lecturer \\ of Ivan Kozhedub Kharkiv National \\ Air Force University, \\ Kharkiv, Ukraine \\ https://orcid.org/0000-0003-3049-2547 \\ Dmitro Litovchenko \\ $\mathrm{PhD}$ in Engineering \\ Senior Lecturer \\ of Ivan Kozhedub Kharkiv National \\ Air Force University, \\ Kharkiv, Ukraine \\ https://orcid.org/0000-0001-5154-6060 \\ Oleksandr Mishukov \\ Associate Professor \\ of Ivan Kozhedub Kharkiv National \\ Air Force University, \\ Kharkiv, Ukraine \\ https://orcid.org/0000-0001-6101-122X
}

\title{
ОЦЕНКА ЭФФЕКТИВНОСТИ БОЕВОГО ПРИМЕНЕНИЯ РАЗВЕДЫВАТЕЛЬНО-УДАРНОЙ СИСТЕМЫ С УЧЕТОМ ТЕХНИЧЕСКИХ ХАРАКТЕРИСТИК СИСТЕМ РАЗВЕДКИ И УПРАВЛЕНИЯ
}

\author{
С.С. Рязанцев, Д.М. Литовченко, А.М. Мишуков
}

В настоящее время в условиях быстрого развития вооружения и военной техники, повышение интенсивности проиесса ведения боевых действий (операций) много внимания уделяется вопросам оценки эффективности разведывательно-ударных систем, состоящих из систем разведки, управления и средств огневого поражения. В статье рассмотрен процесс функиионирования разведывательно-ударной системы, с учетом влияния технических характеристик системы разведки и системы управления с иелью разработки методики оценки эффективности ее боевого применения.

Ключевые слова: разведывательно-ударная система, система разведки, системы управления, огневые средства, эффективность.

\section{EVALUATION OF EFFICIENCY OF FIRE DEVELOPMENT MEANSOF RESEARCH AND IMPACT SYSTEM TAKING INTO ACCOUNT TECHNICAL AND TECHNICAL DATA SHEETS}

\author{
S. Riazantsev, D. Litovchenko, O. Mishukov
}

The experience of local armed conflicts, the Anti-Terrorist Operation (Joint Forces Operation) in eastern Ukraine has shown that the peculiarity of modern military conflicts on the example of the Armenian-Azerbaijani conflict in NagornoKarabakh is the active use of reconnaissance and strike systems capable of detecting, recognizing and recognizing a large number of targets in enemy territory, reducing the time from detection of the target to hit it to a few minutes. Today, during the rapid development of armaments and military equipment, increasing the intensity of the process of combat operations (operations), much attention is paid to assessing the effectiveness of reconnaissance and strike systems, which consist of reconnaissance, control and fire means. The article considers the process of functioning of the reconnaissance and strike system, taking into account the influence of the technical characteristics of the reconnaissance system and the control system in order to develop a methodology for evaluating the effectiveness of its combat use. The calculations given in the article were carried out under the assumption that the reconnaissance and strike system operates autonomously, in the absence of external control influences in order to hit the maximum number of targets in the area of responsibility. The probability of firing at a target was chosen as an indicator of the effectiveness of the reconnaissance and strike system. Thus, the article analyzes the impact of technical characteristics of the reconnaissance and control system on the effectiveness of combat use of fire-fighting reconnaissance and strike system, proposes a method for assessing the effectiveness of combat use of fire-fighting reconnaissance and strike system taking into account the technical characteristics of the reconnaissance system and control system. The developed technique allows to identify the influence of technical characteristics of the reconnaissance system and fire control system on the effectiveness of the reconnaissance and strike system as a whole and to substantiate the requirements for tactical and technical characteristics of advanced weapons systems of their reconnaissance, control and fire destruction systems. In the future, the results of evaluating the effectiveness of combat use of reconnaissance and strike systems, taking into account the technical characteristics of reconnaissance and control systems, are recommended and can be used to prepare and form a simulation model to assess the probability of damage to combat vehicles of mobile reconnaissance systems support (decision-making) by the commander of different (relevant) levels.

Keywords: reconnaissance and strike system, reconnaissance system, control systems, fire means, efficiency. 